\title{
Assessing Insights and Practices among Graduates to Signify the Need for Dental Ergonomics within the Dental Curriculum: A Cross-Sectional Survey
} \author{
Zohaib Khurshid ${ }^{4}$ Samira Adnan ${ }^{5}$ \\ ${ }^{1}$ Institute of Medical Education, Jinnah Sindh Medical University, \\ Karachi, Pakistan \\ 2Dental Education \& Research Department, Altamash Institute of \\ Dental Medicine, Karachi, Pakistan \\ ${ }^{3}$ Maternal and Child Health Department, Interactive Research and \\ Development (IRD), Karachi, Pakistan \\ ${ }^{4}$ Prosthodontics and Implantology, College of Dentistry, King Faisal \\ University, Al-Ahsa, Saudi Arabia \\ ${ }^{5}$ Department of Operative Dentistry, Sindh Institute of Oral Health \\ Sciences, Jinnah Sindh Medical University, Karachi, Pakistan
}

Shaur Sarfaraz ${ }^{1, \odot ~ M o h s i n a ~ H a m i d ~ G o r e ~}{ }^{2}$ Marium Abbas Askari ${ }^{2}$ Shayan Imran

Eur Dent Res Biomater ] 2020;1:51-56

\author{
Address for correspondence Shaur Sarfaraz, BDS, MBA, MHPE \\ (scholar), Institute of Medical Education, Jinnah Sindh Medical \\ University, Karachi, Pakistan (e-mail: shaur.sarfaraz@jsmu.edu.pk).
}

\begin{abstract}
Keywords

- dental graduates

- ergonomics

- dental curriculum

Objectives The aim of this study was to assess the knowledge, attitude, and practices of ergonomics among dental graduates in Karachi.

Materials and Methods A descriptive cross-sectional study was conducted at Altamash Institute of Dental Medicine from December 2019 to April 2020. The study was performed among 174 dental graduates (house officers) in Karachi, using a modified, validated, closed-ended questionnaire. For statistical analysis, SPSS software (version 21) was used for descriptive statistics such as percentages and frequencies. The tests applied were independent $t$-test and Pearson's correlation to compare and check the correlation between the variables. The $p$-value used was $\leq 0.05$.

Results Among 200 dental graduates, only 174 responses were analyzed in SPSS version 21 . Females $(78.2 \%)$ were more in number than males $(21.8 \%)$, with most of them aged $>23$ years $(59.1 \%)$. Of the study population, $78.7 \%$ graduates worked 4 to 6 hours per day, and more than half of the graduates (58\%) did not do physical exercise outside work. Furthermore, we found that the majority of responders had a fair knowledge of ergonomic principles, where a total of 134 (77\%) dental graduates had a positive attitude towards its implementation, however this was not reflected in their practices as $128(73.6 \%)$ graduates has poor practices related to ergonomics. It was also found that knowledge and practices of ergonomics had a weak but significant correlation $(r=0.263, p=0.001)$. Moreover, males were more positive about implementing and practicing ergonomics then females with a significant association $(p=0.001)$.
\end{abstract}

DOI https://doi.org/ $10.1055 / s-0040-1721538$ (c) 2020. European Dental Research and Biomaterials Journal.

This is an open access article published by Thieme under the terms of the Creative Commons Attribution-NonDerivative-NonCommercial-License, permitting copying and reproduction so long as the original work is given appropriate credit. Contents may not be used for commercial purposes, or adapted, remixed, transformed or built upon. (https://creativecommons.org/licenses/by-nc-nd/4.0/)

Thieme Medical and Scientific Publishers Pvt. Ltd., A-12, 2nd Floor, Sector 2, Noida-201301 UP, India 
Conclusions A majority of the dental graduates (house officers) in this present study had a reasonable knowledge of ergonomics and its principles also showed positivity but an only small number of them practiced dental ergonomics. This study recommends the need for including dental ergonomics in the academic curriculum of clinical years of both dental undergraduate and postgraduate studies and also conducts workshops to develop faculty to reinforce its importance.

\section{Introduction}

The field of dentistry majorly revolves around the psychomotor domain. Hence, the compulsory skills and competencies needed to handle and treat unhealthy conditions of the oral cavity require working on a dental chair at a fixed position for long hours. Therefore, in the absence of good physical health, it is nearly impossible to perform dental procedures on patients efficiently. ${ }^{1}$ Thus, dentists must be aware of all the basic principles that will enable him to maintain adequate physical health for an extended period, allowing them to perform at maximum capacity when treating patients.

Ergonomics includes the basic principles required to maintain physical health in any field, especially those with substantial physical activity. The term ergonomics is a combination of two Greek words, "Ergon" that means work, and "nomos" means norms, rules, or laws. ${ }^{2}$ The International Association of Ergonomics defined this term in the year 2000 as "a scientific discipline that aims at a fundamental understanding of the interactions between humans and other components of a system." They further explain that ergonomic principles help to increase the productivity and quality of work at the same time, ensuring the safety of the individual while decreasing any chances of errors that may lead to unnecessary fatigue. ${ }^{3}$ This term is now being used in dentistry more than ever. The reason is that dentists all around the world are suffering chronic physical detrimental effects due to lack of knowledge of ergonomic principles. At least $64-93 \%$ of dentists and dental students suffer from musculoskeletal disorders (MSDs) or pain with most effected areas are neck and back region evident in the studies conducted globally. ${ }^{4,5}$

There is an increased demand for dental care across the world as an increasing number of people become aware of the risks related to poor oral hygiene. This has led to elevated work pressure and stress on dental practitioners who work for long hours to fulfill their duties. It has been proven that long-lasting stress on the human body causes unwanted muscle contractions eventually eliciting pain, significantly affecting the back muscles. ${ }^{6}$ Dental practitioners are excessively experiencing constant use of detrimental operating positions, continuous strain on vision, long hours of fixed posture, precise movements of the hands, handling of specific instruments and tools, unsupported elevated arms, uncomfortable working environments, and psychological stress. Hence, dentists have become more prone to MSDs with the back and neck muscles being most affected, followed by shoulder pain and headaches. ${ }^{7}$ In a study conducted in Rawalpindi in 2016, it was deduced that over $70 \%$ of the participating dentists had MSDs with lower back pain being the most frequent followed by neck pain and pain in the wrists. ${ }^{8}$ Therefore, dentists have a heightened chance of compromised health due to their professional and practices.

There have been reports of certain risk factors that may aggravate these MSDs in dentists around the globe. In a study conducted in 2013, it was deduced that the difference in gender has no significant effect on the frequency of MSDs. However, an increased number of working hours per day and the number of patients treated were directly proportional to increased MSDs. Furthermore, the number of years in practice was inversely proportional to the frequency of these disorders, possibly due to improvements made with experience in ideal working postures. ${ }^{9}$ In another study, it was recorded that the age, working hours per day, and the years of clinical practice did not significantly affect the frequency of these disorders. However, an increased number of patients led to a $100 \%$ prevalence of MSDs. ${ }^{10}$ A study conducted in Jordan in 2011 concluded that these disorders were more prevalent with increasing age and years of practice. ${ }^{11}$ Hence, it can be concluded that the above factors do have some effect on the frequency and prevalence of these disorders in dentists.

Keeping in mind the health hazards that pose a challenge to the well-being of dentists and dental students alike, they must hone their skills under the guidance of ergonomic principles. It has been proven that a lack of understanding of the ergonomic tenets has a pivotal role in causing health issues such as certain work-related MSDs. ${ }^{12,13}$ Therefore, a balanced comprehension of ergonomics and proper implementation of its principles can alleviate the risk of health hazards in dental practice. ${ }^{14,15}$

The above facts indicate that the knowledge of ergonomics and the ability to apply it during dental practice are of great importance to sustain a healthy working system in which both practitioners and students can perform efficiently and better serve the community. If ergonomic principles are inculcated in the minds of the future practitioners when they are students, it will go a long way in ensuring that the physical well-being of dentists is maintained during their lifelong practices. Thus, this study emphasizes assessing the knowledge, attitude, and practices (KAP) of ergonomics among dental graduates. 


\section{Materials and Methods}

A descriptive cross-sectional study was conducted in Altamash Institute of Dental Medicine with the use of a structured questionnaire, modified and piloted among 20 participants giving Cronbach's $\alpha$ value of 0.882 (17 items of knowledge: 0.916, 6 items of attitude: 0.918, and 10 items of practice: 0.813 ). The ethical approval was taken by the institution (Ethical Review \#: AIDM/EC/02/19/22). The questionnaire was distributed among all individuals doing 1-year house job between December 2019 and January 2020. The sample size was calculated by Open Epi Software (confidence interval: 90\%), population size ( $n$ ) was 450 , hypothesized \% frequency of outcome factor in the population (p): $50 \% \pm 5$ and confidence limit as \% of 100 (d): $5 \%$ which gave the sample size of 170 .

The questionnaire was distributed to 200 house surgeons from which 174 forms with no missing data were included in the study. The subjects included in the study were all house officers (fresh dental graduates) who were currently practicing and had given their consent to participate in the study. A year back and irregular graduates were not included in the study. Each candidate was informed of the purpose, and the benefits of the research and a guarantee of confidentiality was given prior to the data collection. Only after acquiring a verbal and signed consent from the candidates the responses were included in the study.

\section{Study Instrument}

The closed-ended questionnaire used was divided into two sections. The first section was concerned with demographic details, work duration, and physical activity outside work. The second included three subsections. The first subsection had 17 questions, which dealt with the knowledge of ergonomic principles, the second subsection dealt with a total of 6 questions about the attitude of the candidates regarding the inclusion of these principles in their undergraduate studies, and subsection three had ten questions about the application of these principles in routine practice.

The KAP of the house officers regarding ergonomic principles was assessed via different 5-point Likert scales. Knowledge was scored on 0-4: not at all aware, slightly aware, moderately aware, very aware, and lastly extremely aware.

The attitude was scored on $0-4$ : strongly disagree, disagree, neutral, agree and strongly agree. Similarly, for application of the principles that is practice, $0-4$ (never, rarely, often, very often, and always) scale was used.

\section{Scoring of Each Variable}

The total score for the knowledge of the house officers as deduced from the Likert scale ranged from 0 to 68 score (17 questions in total). A score of $\geq 75 \%(\geq 51)$ was considered good knowledge, a score between 50 and $<75 \%(34-50)$ indicated fair knowledge, while a score of $<50 \%(<34)$ was having poor knowledge of the principles.
The total score for their attitude ranged from 0 to 24 scores (6 questions in total). Any candidate who scored $\geq 50 \%(\geq 12)$ was considered having a positive attitude; those who scored less than $50 \%$ ( $\leq 12$ ) had a negative attitude toward ergonomics and its principles.

For the application, the score ranged from 0 to 40 scores (10 questions in total). Candidates scoring $\geq 50 \%$ ( $\geq 20$ ) were considered as having good practice, while those with a score of less than $50 \%(<20)$ had a poor practice toward the application of the principles.

\section{Data Analysis}

After the data collection, the SPSS software (version 21) was used for descriptive statistics such as percentages and frequencies. The tests applied were independent $t$-test and Pearson's correlation to compare and check the correlation between the variables. The $p$-value used was $\leq 0.05$.

\section{Results}

- Table 1 displays descriptive statistics of house officers in which the males were the minority as compared with the females, and most of them were in the age group of $>23$ years. Majority of them were working for 4 to 6 hours, while others were working for 7 to 9 hours. More than half of the house officers did not do any physical exercise outside their work.

- Table 2 shows that almost half of the participants had a fair knowledge of ergonomics, but their knowledge was not sufficient as it should have been upon graduation. However, they were very positive toward ergonomics and its principles. According to this study, participants thought that ergonomics should be a part of the curriculum. They believed that every undergraduate student and graduate dentist should use principles of ergonomics while practicing dentistry as

Table 1 Descriptive statistics and characteristics of the participants

\begin{tabular}{|c|c|}
\hline Characteristics, $n=174$ & Frequencies (\%) \\
\hline \multicolumn{2}{|l|}{ Age } \\
\hline $\begin{array}{l}\cdot \leq 23 \\
\cdot \leq 23\end{array}$ & $\begin{array}{l}71(40.8) \\
103(59.1)\end{array}$ \\
\hline Mean \pm SD & $23.64 \pm 0.861$ \\
\hline \multicolumn{2}{|l|}{ Work duration } \\
\hline - 4-6h & $137(78.7)$ \\
\hline - 7-9h & $37(21.3)$ \\
\hline Mean \pm SD & $5 . .64 \pm 1.343$ \\
\hline \multicolumn{2}{|l|}{ Gender } \\
\hline - Male & $38(21.8)$ \\
\hline - Female & $136(78.2)$ \\
\hline \multicolumn{2}{|l|}{ Physical exercise } \\
\hline - Yes & $73(42)$ \\
\hline - No & $101(58)$ \\
\hline
\end{tabular}

Abbreviation: SD, standard deviation. 
Table 2 Descriptive statistics with total score's mean of knowledge, attitude, and practices of the participants

\begin{tabular}{|l|l|l|l|l|l|}
\hline \multirow{2}{*}{ Variables } & \multicolumn{2}{|l|}{ Frequencies (\%), $n=174$} & \multicolumn{2}{l|}{$\begin{array}{l}\text { Scores } \\
\text { Mean } \pm \text { SD }\end{array}$} & Value \\
\hline \multirow{2}{*}{ Knowledge } & Poor & Fair & Good & $1.79 \pm 0.764$ & 0.001 \\
\cline { 2 - 3 } & $62(35.6)$ & $90(51.7)$ & $22(12.6)$ & \\
\hline \multirow{2}{*}{ Attitude } & Positive & Negative & & \\
\cline { 2 - 3 } & $134(77)$ & $40(23)$ & & \\
\hline Practices & Good & Bad & & \\
\cline { 2 - 3 } & $46(26.4)$ & $128(73.6)$ & & \\
\hline
\end{tabular}

Abbreviation: SD, standard deviation.

the lack ergonomics in their practices is compromising their physical health.

- Table 3 displays the relationship between KAP of the dental house officers and ergonomics. It was appreciated that almost half of the house officers in - Table 2 carry fair knowledge about ergonomics, and most of them have positive attitudes. Still, - Table 3 shows that there was a negative and weak correlation between attitude and knowledge. However, most of the house officers with poor practice had a significantly positive and weak correlation with knowledge but an incredibly negative and weak correlation with attitude.

- Table 4 shows the KAP of the participants and its relationship with sociodemographic characteristics, work duration (hours), and practicing physical exercise. Less than half of the house officers with the age of 23 or less had a fair knowledge of ergonomic principles, compared with $65 \%$ of students more than 23 years, with no significant association between knowledge and age. There was no difference between male and females; both genders had good knowledge with no significant association between gender and knowledge. There was also no significant association between work duration and doing physical exercise. Students aged less than 23 years and more than 23 years had a positive attitude with no significant association between age and attitude. Male and female house officers had a positive attitude toward ergonomics with a significant association between gender and attitude.

Moreover, between work duration or practicing physical exercises among students, there were positive attitudes toward ergonomics, but there was no significant association. The age groups, males, and females had poor practices without significant association. There were poor practices found with no significant association between work duration and doing physical exercise.

\section{Discussion}

Incorporating the ergonomic principles in routine dental practice helps dental students to correct the way of performing dental procedures, which would minimize the effect of any risks or hazards to their physical health during handling and treating patients, thus ensuring long-term quality performance and patient safety. ${ }^{16}$ Unfortunately, ergonomics is not vastly practiced and is neglected. It is also not a part of the dental curriculum for dental postgraduate and undergraduate students in many countries. As a result, fresh
Table 3 Correlation between knowledge, attitude, and practices of ergonomics

\begin{tabular}{|l|l|l|}
\hline Variables & $\boldsymbol{r}$ & $\boldsymbol{p}$-Value \\
\hline Knowledge and practice & 0.263 & 0.001 \\
\hline Knowledge and attitude & -0.107 & 0.159 \\
\hline Practice and attitude & -0.321 & 0.001 \\
\hline
\end{tabular}

graduates face a lot of musculoskeletal issues that hinder their practice and reduce their performance at initial stages of their career as their body posturing and handling during practicing dentistry and treating patients are not according to ergonomic principles. ${ }^{17,18}$ This problem is evident in a study conducted in Sindh Karachi in 2017, which reported high prevalence of MSDs in dentists. ${ }^{19}$ In another study, it was found that over $92 \%$ of the surveyed dentists experienced MSDs. It was concluded that limited ergonomics in the work environment of dentists results in MSDs, and its prevalence is very high. ${ }^{20}$ These MSDs later lead to early retirements as is evident from this study which concluded that $55 \%$ of ill health retirement in dental practitioners were due to MSDs. ${ }^{21}$

Furthermore, lack of physical activity outside work and long hours of work duration seem to increase the chances of the same condition. This present study highlighted that majority of the participants had no physical activity outside work and were working for at least 4 to 5 hours every day. With that, the present study also revealed that more than half of the house surgeons had average knowledge and considerably positive attitude toward ergonomics in routine dental practice that was also signified by a recent study conducted in a dental institute of Lithuanian, on international students considering dental ergonomics essential to practice in undergraduate studies as students do have positive attitude to practice ergonomics. ${ }^{22}$ However, they lack ergonomics in daily practice, as is evident in the results. Similar findings can be appreciated in a study conducted among undergraduates of Faculty of Dentistry, Tanta University, Egypt 2018 in which they experienced same results for knowledge and attitude but $95.4 \%$ had the poor practice of ergonomics ${ }^{23}$ that showed that even though the respondents were eager to adopt and consequently use the principles for their betterment, they were not able to do so. The current study also highlighted that there was no significant relationship between knowledge and attitude or attitude and practice of ergonomic principles. Although there was a significant yet 
Table 4 Knowledge, attitude, and practices of house officers according to their sociodemographic characteristics, work duration, and physical exercise

\begin{tabular}{|c|c|c|c|c|c|c|c|}
\hline \multirow[t]{2}{*}{ Characteristics } & \multirow[t]{2}{*}{$n(\%)$} & \multicolumn{2}{|c|}{ Knowledge } & \multicolumn{2}{|c|}{ Attitude } & \multicolumn{2}{|c|}{ Practice } \\
\hline & & Mean \pm SD & p-Value & Mean \pm SD & $p$-Value & Mean \pm SD & $p$-Value \\
\hline $\begin{array}{l}\text { Age } \\
\cdot<23 \\
\cdot>23\end{array}$ & $61(35) 113(65)$ & $\begin{array}{l}1.80 \pm 0.676 \\
1.76 \pm 0.808\end{array}$ & 0.063 & $\begin{array}{l}3.06 \pm 0.801 \\
2.71 \pm 0.898\end{array}$ & 0.273 & $\begin{array}{l}2.08 \pm 0.603 \\
2.23 \pm 0.658\end{array}$ & 0.224 \\
\hline $\begin{array}{l}\text { Gender } \\
\text { - Female } \\
\text { - Male }\end{array}$ & $136(78) 38(22)$ & $\begin{array}{l}1.80 \pm 0.739 \\
1.74 \pm 0.857\end{array}$ & 0.491 & $\begin{array}{l}2.81 \pm 0.970 \\
2.93 \pm 0.411\end{array}$ & $0.001^{\mathrm{a}}$ & $\begin{array}{l}2.21 \pm 0.206 \\
2.06 \pm 0.569\end{array}$ & 0.391 \\
\hline $\begin{array}{l}\text { Physical activity outside work } \\
\text { - No } \\
\text { - Yes }\end{array}$ & $101(58) 73(42)$ & $\begin{array}{l}1.73 \pm 0.743 \\
1.87 \pm 0.791\end{array}$ & 0.432 & $\begin{array}{l}2.80 \pm 0.959 \\
2.88 \pm 0.759\end{array}$ & 0.134 & $\begin{array}{l}2.19 \pm 0.664 \\
2.17 \pm 0.614\end{array}$ & 0.341 \\
\hline $\begin{array}{l}\text { Work duration } \\
\text { - } 4-6 \mathrm{~h} \\
\text { - } 7-9 \mathrm{~h}\end{array}$ & 137(79) 37(21) & $\begin{array}{l}1.74 \pm 0.782 \\
1.99 \pm 0.666\end{array}$ & 0.077 & $\begin{array}{l}2.87 \pm 0.859 \\
2.70 \pm 0.951\end{array}$ & 0.252 & $\begin{array}{l}1.37 \pm 0.214 \\
2.32 \pm 0.670\end{array}$ & 0.862 \\
\hline
\end{tabular}

Abbreviation: SD, standard deviation.

andicates significant difference.

weak association between knowledge and practice, it is none the less shows that knowledge of ergonomics does influence the dental practice of the practitioners. A previous study conducted in dental colleges of India by Karibasappa and Rajeshwari ${ }^{24}$ found that the candidates had adequate knowledge and a positive attitude. Still, they did not practice it as much as required, which resulted in body pains, increased musculoskeletal stress, and lack of efficient performance. ${ }^{17,25}$

Hence, it is very crucial to conduct studies that gauge the KAP of fresh graduates to save them from future health issues by introducing ways to facilitate the inclusion of ergonomic principles into their curriculum during their clinical years. ${ }^{26}$ In many studies, it was recommended, and students willingly agreed to the inclusion of ergonomics in their academic curriculum and to attend workshops to further enhance their skills.22-26 With this kind of positive attitude, it will be easier to incorporate ergonomics in routine dental practice, which can also increase awareness of MSDs. This requires significant effort and consistency in the evaluation of the dental education program and implementation of policies at all levels. ${ }^{27,28}$

However, there are some limitations that need to be addressed in further research. As the study was conducted in only one institute, the results cannot be generalized properly. To fill the knowledge gaps, further qualitative studies must be conducted to highlight the reasons behind the results obtained in this study. Also, a larger sample will ensure better reliability and will further strengthen the results and increase knowledge about ergonomics.

\section{Conclusions}

Principles of ergonomics should be an essential part of clinical years of dental curriculum for both undergraduate and postgraduate students, and accrediting bodies should implement these. It should not only be included in their curriculum, but for successful implementation, faculty development workshops should be conducted at all levels to ensure the reinforcement of these principles. The proper emphasis on these principles will improve the mental and physical health of future dentists that will reduce the effects of work-related MSDs and will also help to improve patient safety.

\section{Funding}

None.

\section{Conflict of Interest}

None declared.

\section{Acknowledgments}

The authors would like to thank administrative and technical support we were given by Altamash Institute of Dental Medicine.

\section{References}

1 Puriene A, Janulyte V, Musteikyte M, Bendinskaite R. General health of dentists. Literature review. Stomatologija 2007;9 (1):10-20

2 Santos AL, Silva SDC. Ergonomic intervention in the manufacturing process of chemicals in a company of the Petrogas/ Sergipe network. Gest Prod 2017;24(3):488-500

3 Mir A, Rajab M. Ergonomics in dental practice. IJSR 2015; 4(9);154-155

4 Sachdeva A, Bhateja S, Arora G. Ergonomics in dentistry: A comprehensive review. J Dent Res Rev 2020;7(1):32-35

5 Harutunian K, Gargallo-Albiol J, Figueiredo R, Gay-Escoda C. Ergonomics and musculoskeletal pain among postgraduate students and faculty members of the School of Dentistry of the University of Barcelona (Spain). A cross-sectional study. Med Oral Patol Oral Cir Bucal 2011;16(3):e425-e429

6 Al Wazzan KA, Almas K, Al Shethri SE, Al-Qahtani MQ. Back \& neck problems among dentists and dental auxiliaries. J Contemp Dent Pract 2001;2(3):17-30

7 Munaga S, Rawtiya M, Khan S, Chitumalla R, Kubagiri SR, Sajjan P. Assessment of knowledge, practices, and work place condition related to ergonomics among dental students of Bhopal city - A questionnaire study. J Orofac Sci 2013;5(2):109-113 
8 Rehman B, Aslam A, Ali A, Tariq A. Ergonomic hazards to dental surgeons: a cross-sectional study. Pak Oral Dent J 2020; 36(1):168-171

9 Mansoor SN, Yousaf O, Rathore FA, Azad AA, Ishfaque Q. Frequency of musculoskeletal disorders among dental professionals at armed forces institute of dentistry. J Pak Dent Assoc 2013;22(3):185-188

10 Muralidharan D, Fareed N, Shanthi M. Musculoskeletal disorders among dental practitioners: does it affect practice? Epidemiol Res Int 2013;2013:1-6

11 Barghout NH, Al-Habashneh R, AL-Omiri MK. Risk factors and prevalence of musculoskeletal disorders among Jordanian dentists. J Med J 2011;45(2):195-204

12 Hodacova L, Sustova Z, Cermakova E, Kapitan M, Smejkalova J. Self-reported risk factors related to the most frequent musculoskeletal complaints among Czech dentists. Ind Health 2015;53(1):48-55

13 Khan SA, Chew KY. Effect of working characteristics and taught ergonomics on the prevalence of musculoskeletal disorders amongst dental students. BMC Musculoskelet Disord 2013;14:118 doi:10.1186/1471-2474-14-118

14 Sharma H, Sharma A, Khattri S. The major risk factors of musculoskeletal pain amongst dental students--a prevalence based study. RJLBPCS 2018;4(4):188-196

15 Shaik AR, Rao SB, Husain A, D'sa J. Work-related musculoskeletal disorders among dental surgeons: a pilot study. Contemp Clin Dent 2011;2(4):308-312

16 Mulimani P, Hoe VC, Hayes MJ, Idiculla JJ, Abas AB, Karanth L. Ergonomic interventions for preventing musculoskeletal disorders in dental care practitioners. Cochrane Database Syst Rev2018;10(10):CD011261doi:10.1002/14651858.CD011261. pub2

17 Radanović B, Vučinić P,Janković T, Mahmutović E, Penjašković D. Musculoskeletal symptoms of the neck and shoulder among dental practitioners. J Back Musculoskeletal Rehabil 2017; 30(4):675-679
18 Das H, Motghare V, Singh M. Ergonomics in dentistry: narrative review. Int J Appl Dent Sci. 2018;4(4):104-110

19 Khan RS, Ahmad F, Merchant MS. Prevalence of work related musculoskeletal disorders (MSD) among dentists. Int J Contemp Med Res 2017;4(5):1208-1211

20 Kierklo A, Kobus A, Jaworska M, Botuliński B. Work-related musculoskeletal disorders among dentists - a questionnaire survey. Ann Agric Environ Med 2011;18(1):79-84

21 Brown J, Burke FJ, Macdonald EB, et al. Dental practitioners and ill health retirement: causes, outcomes and re-employment. Br Dent J 2010;209(5):E7

22 Pîrvu C, Pătraşcu I, Pîrvu D, Ionescu C. The dentist's operating posture-ergonomic aspects. J Med Life 2014;7(2):177

23 El-Sallamy RM, Atlam SA, Kabbash I, El-Fatah SA, El-Flaky A. Knowledge, attitude, and practice towards ergonomics among undergraduates of Faculty of Dentistry, Tanta University, Egypt. Environ Sci Pollut Res Int 2018;25(31):30793-30801

24 Karibasappa GN, Rajeshwari K. Dentists' knowledge, attitude and behavior towards the dental ergonomics. IOSR J Dent Med Sci 2014;13(5):86-89

25 Anu V, Babu AMS, Kumar PDM. Insights about dental ergonomics among dental students: the need of the hour to recommend dental ergonomics in academic curriculum. J Adv Oral Res 2018;9(1-2):49-54

26 Siddiqui TM, Wali A, Khan OH, Khan M, Zafar F. Assessment of knowledge, practice, and work environment related to ergonomics among dental students and dental practitioners. Int J Contemp Dent Med Rev 2016 Article ID: 040316 doi: 10.15713 /ins ijcdmr.100

27 Partido BB, Henderson RP, Kennedy M. Improving the awareness of musculoskeletal disorder risks among dental educators. J Dent Educ 2020;84(1):5-12

28 Hafeez K, Wahaj A, Zafar M. Evolving medical and dental education system in Pakistan. Pak Armed Forces Med J 2015;65(4):564-567. https://pafmj.org/index.php/PAFMJ/ article/view/1046 Accessed Oct 20, 2020 